\title{
Global transcriptional response to vancomycin in Mycobacterium tuberculosis
}

Correspondence
Riccardo Manganelli
riccardo.manganelli@unipd.it

Received 1 October 2008

Revised 5 December 2008

Accepted 10 December 2008

\section{Roberta Provvedi, ${ }^{1}$ Francesca Boldrin, ${ }^{2}$ Francesco Falciani, ${ }^{3}$ Giorgio Palù ${ }^{2}$ and Riccardo Manganelli ${ }^{2}$}

\author{
${ }^{1}$ Department of Biology, University of Padua, 35100 Padua, Italy \\ ${ }^{2}$ Department of Histology, Microbiology and Medical Biotechnologies, University of Padua, 35100 \\ Padua, Italy \\ ${ }^{3}$ School of Biosciences, University of Birmingham, Edgbaston, Birmingham B15 2TT, UK
}

\begin{abstract}
In order to gain additional understanding of the physiological mechanisms used by bacteria to maintain surface homeostasis and to identify potential targets for new antibacterial drugs, we analysed the variation of the Mycobacterium tuberculosis transcriptional profile in response to inhibitory and subinhibitory concentrations of vancomycin. Our analysis identified 153 genes differentially regulated after exposing bacteria to a concentration of the drug ten times higher than the MIC, and 141 genes differentially expressed when bacteria were growing in a concentration of the drug eightfold lower than the MIC. Hierarchical clustering analysis indicated that the response to these different conditions is different, although with some overlap. This approach allowed us to identify several genes whose products could be involved in the protection from antibiotic stress targeting the envelope and help to confer the basal level of M. tuberculosis resistance to antibacterial drugs, such as Rv2623 (UspA-like), Rv0116c, PE20-PPE31, PspA and proteins related to toxin-antitoxin systems. Moreover, we also demonstrated that the alternative sigma factor $\sigma^{\mathrm{E}}$ confers basal resistance to vancomycin, once again underlining its importance in the physiology of the mycobacterial surface stress response.
\end{abstract}

\section{INTRODUCTION}

Mycobacterium tuberculosis remains one of the world's most prevalent and serious pathogens. It is estimated that every year 2 million people die as a direct result of tuberculosis and that there is a reservoir of 2 billion cryptically infected people (Dye et al., 1999). Of these asymptomatic carriers, around $5 \%$ will develop active disease at some stage in their lives and in doing so will contribute to the ongoing transmission of infection (Raviglione, 2003). The recent emergence of multidrugresistant (MDR) and extensively drug-resistant (XDR-TB) strains (Gandhi et al., 2006) has raised the importance of searching for alternative targets to develop new antimycobacterial drugs.

Due to the importance of its physiological role and its difference from the eukaryotic cell surface, the bacterial cell

Abbreviations: HCL, hierarchical clustering; SAM, significance analysis of microarrays.

The data discussed in this publication have been deposited in the NCBI Gene Expression Omnibus under GEO Series accession number GSE12364.

Five supplementary tables are available with the online version of this paper. wall is one of the best candidates in the search for new drug targets. A large number of antibacterial drugs currently in use are directed against surface components or metabolic pathways that are involved in their synthesis. For example, $\beta$-lactams, cephalosporins, glycopeptides, phosphomycin, bacitracin and cycloserine inhibit peptidoglycan biosynthesis, while polymyxin interferes with the cell-membrane structure. Moreover, compounds such as isoniazid, pyrazinamide, ethambutol and ethionamide target typical components of the mycobacterial cell surface. In spite of a good knowledge of the chemical composition of the mycobacterial surface, not much is known about its organization and physiology (Barry, 2001). The recent demonstration of the presence of an outer membrane will surely boost research in this field (Hoffmann et al., 2008; Zuber et al., 2008).

One strategy to study bacterial surface physiology is to characterize the variation of the bacterial transcriptional profile in response to exposure to compounds able to perturb surface homeostasis. This approach has been successfully used to study the global transcriptional response of Bacillus subtilis and Staphylococcus aureus in response to several inhibitors of peptidoglycan biosynthesis (Cao et al., 2002; Mascher et al., 2003; Utaida et al., 2003), and in $M$. tuberculosis to study the transcriptional response to the 
detergent SDS (Manganelli et al., 2001) and to the mycolic acid biosynthesis inhibitor isoniazid (Wilson et al., 1999). These experiments contributed to the understanding of the physiological mechanisms used by bacteria to maintain surface homeostasis and to identify several potential targets for the development of new antibacterial drugs.

In this work we used this approach to characterize the variation of the $M$. tuberculosis global transcriptional profile in response to inhibitory and subinhibitory concentrations of vancomycin. Our analysis has identified a significant transcriptional response associated with bacteria exposed to a concentration of the drug ten times higher than the MIC (153 genes differentially regulated) as well as bacteria growing in a concentration of the drug eightfold lower than the MIC (141 genes differentially regulated).

\section{METHODS}

Bacterial strains and growth conditions. M. tuberculosis strains H37Rv, ST28 (sigE mutant) and ST29 (sigE complemented mutant) (Manganelli et al., 2001) were grown in Middlebrook 7H9 (Difco) supplemented with $10 \%$ albumin-dextrose-sodium chloride complex (ADN) (Jacobs et al., 1991), $0.2 \%$ glycerol and $0.05 \%$ Tween 80 (Sigma) at $37^{\circ} \mathrm{C}$ in rotating bottles (40 r.p.m.).

Cultures growing in subinhibitory concentrations of vancomycin were obtained by inoculating bacteria in $35 \mathrm{ml} 7 \mathrm{H} 9$ (at an $\mathrm{OD}_{540}$ of 0.05 ) containing $5 \mu \mathrm{g} \mathrm{ml}^{-1}$ of the drug and following their growth until they reached an $\mathrm{OD}_{540}$ between 0.2 and 0.3 . Cultures exposed to inhibitory concentrations of vancomycin were obtained by adding $400 \mu \mathrm{g} \mathrm{ml}^{-1}$ of the drug to $35 \mathrm{ml}$ bacterial cultures grown in $7 \mathrm{H} 9$ to an $\mathrm{OD}_{540}$ of $0.2-$ 0.3 and incubating at $37{ }^{\circ} \mathrm{C}$ for an additional 1 or $4 \mathrm{~h}$.

RNA extraction and cDNA labelling. Bacterial cultures were centrifuged for $5 \mathrm{~min}$ at $2500 \mathrm{~g}$. After removing the supernatant, pellets were frozen on dry ice and stored at $-80{ }^{\circ} \mathrm{C}$. The RNA from the frozen pellets was extracted following standard protocols as previously described (Maciag et al., 2007). Fluorescently labelled cDNAs were produced as previously described (Provvedi et al., 2008) by reverse transcription (RT) of total RNA with Superscript II (Invitrogen Life Technologies) in the presence of Cy3-dUTP or Cy5-dUTP (Amersham Pharmacia) by using random hexamers to prime cDNA synthesis (Invitrogen Life Technologies). Fluorescent probes were purified with the CyScribe GFX purification kit (GE Healthcare) and then concentrated to $7.5 \mu \mathrm{l}$ by Microcon YM-30 centrifugal filter devices (Millipore) according to the procedure indicated by the manufacturers.

Microarrays and hybridizations. M. tuberculosis oligoarrays were obtained from the Center for Applied Genomics, International Center for Public Health (Newark, NJ, USA). These microarrays consist of 4295 70-mer oligonucleotides representing 3924 open reading frames (ORFs) from M. tuberculosis strain H37Rv and 371 unique ORFs from strain CDC 1551 that are not present in H37Rv.

Each microarray was incubated in prehybridization solution $(2.8 \%$ BSA, $0.1 \%$ SDS) at $42{ }^{\circ} \mathrm{C}$ for $1 \mathrm{~h}$. The slides were first rinsed in water for $2 \mathrm{~min}$ and then in propan-2-ol for an additional $2 \mathrm{~min}$ before air drying. Competitive hybridizations with equal amounts of purified Cy3/Cy5labelled cDNA (approx. $60 \mathrm{pmol}$ ) were performed in duplicate with both dye arrangements, as previously described (Provvedi et al., 2008).

Fluorescence intensity data from each array were collected with an Affymetrix 428 scanner; the scanned images were finally analysed with ImaGene 4.1 to calculate the median spot intensities.
Data processing and statistical and cluster analysis. Data were normalized with a web-based tool for Diagnosis and Normalization of spotted cDNA MicroArrayData (DNMAD) available at http:// dnmad.bioinfo.cnio.es (Vaquerizas et al., 2005) using the print-tip lowess method after background subtraction. Significance analysis of microarrays (SAM) was performed to identify those genes whose differential expression was considered significant (Tusher et al., 2001). Differentially expressed genes were defined by a $q$-value (percentage chance that the gene is a false positive) $<5 \%$ and a minimum fold difference of \pm 1.5 between control and drug-treated samples. Cluster analysis was carried out by hierarchical clustering (HCL) using a complete linkage agglomeration method applied to a Pearson correlation similarity matrix. Both SAM and HCL were part of the TigerMultiExperiment Viewer package version $3.1(\mathrm{TMeV})$ available at http://www.tm4.org/mev.html (Provvedi et al., 2008).

RT-PCR. Reverse transcription was performed with random primers using murine leukoblastoma virus retrotranscriptase (MULV-RT) (Applied Biosystems). Briefly, $500 \mathrm{ng}$ RNA was denatured at $98{ }^{\circ} \mathrm{C}$ for $2 \mathrm{~min}$ in the presence of the appropriate volume of water and then chilled on ice. The RNA sample was used to prepare $25 \mu \mathrm{l}$ annealing mixture [5.5 $\mathrm{mM} \mathrm{MgCl}_{2}, 0.55 \mathrm{mM}$ (each) dNTPs, $0.25 \mathrm{mmol}$ random hexamers; $32 \mathrm{U}$ MULV, $10 \mathrm{U}$ RNase inhibitor and $1 \times$ reaction buffer (Applied Biosystems)]. Samples were then incubated at $25{ }^{\circ} \mathrm{C}$ for $10 \mathrm{~min}$, at $45{ }^{\circ} \mathrm{C}$ for $50 \mathrm{~min}$, and finally at $95{ }^{\circ} \mathrm{C}$ for $5 \mathrm{~min}$ to allow the annealing of the random hexamers. Quantitative PCR was performed with SYBR green master mix (Applied Biosystems) under the following conditions: $1 \mathrm{~min}$ denaturation at $95{ }^{\circ} \mathrm{C}, 30 \mathrm{~s}$ annealing at $62{ }^{\circ} \mathrm{C}$, and $30 \mathrm{~s}$ extension at $72{ }^{\circ} \mathrm{C}$. Results were normalized to the amount of sigA mRNA, as previously described (Manganelli et al., 1999). RNA samples that had not been reverse transcribed were included in all experiments to exclude significant DNA contamination. For each sample, melting curves were performed to confirm the purity of the products. Sequences of the primers for quantitative RT-PCR are available upon request.

Determination of growth inhibition by disc diffusion assay. $M$. tuberculosis strains were grown to early exponential phase and $100 \mu \mathrm{l}$ culture containing $3 \times 10^{7}$ c.f.u. was spread on $20 \mathrm{ml} 7 \mathrm{H10}$ plates. Paper discs containing $10 \mu \mathrm{l}$ vancomycin at a concentration of $10 \mathrm{mg}$ $\mathrm{ml}^{-1}$ were placed on top of the agar. The diameter of the inhibition zone was measured after 20 days incubation at $37{ }^{\circ} \mathrm{C}$.

\section{RESULTS AND DISCUSSION}

Whole-genome microarrays were employed to profile gene expression in M. tuberculosis $\mathrm{H} 37 \mathrm{Rv}$ in response to inhibitory or subinhibitory concentration of vancomycin. Inhibitory conditions were achieved by exposing bacteria to $400 \mu \mathrm{g}$ vancomycin $\mathrm{ml}^{-1}$, a concentration ten times the MIC (10XMIC). This concentration was chosen in order to determine a rapid arrest of bacterial cell growth (Fig. 1a). A 10X-MIC of vancomycin was also used by Cao et al. (2002) in B. subtilis to identify an inducible defensive response against antibiotics coordinated by alternative sigma factors. Subinhibitory conditions were determined by growing bacteria in the presence of decreasing vancomycin concentrations (twofold serial dilutions) starting from the MIC $\left(40 \mu \mathrm{g} \mathrm{ml}^{-1}\right)$ (data not shown). The concentration of $5 \mu \mathrm{g} \mathrm{ml}^{-1}(1 / 8$-MIC) was chosen since it allowed bacteria to grow with the same profile as untreated cells, although at a reduced rate (Fig. 1b).

In order to choose the time points at which to perform our analysis, we ran a preliminary microarray experiment in 

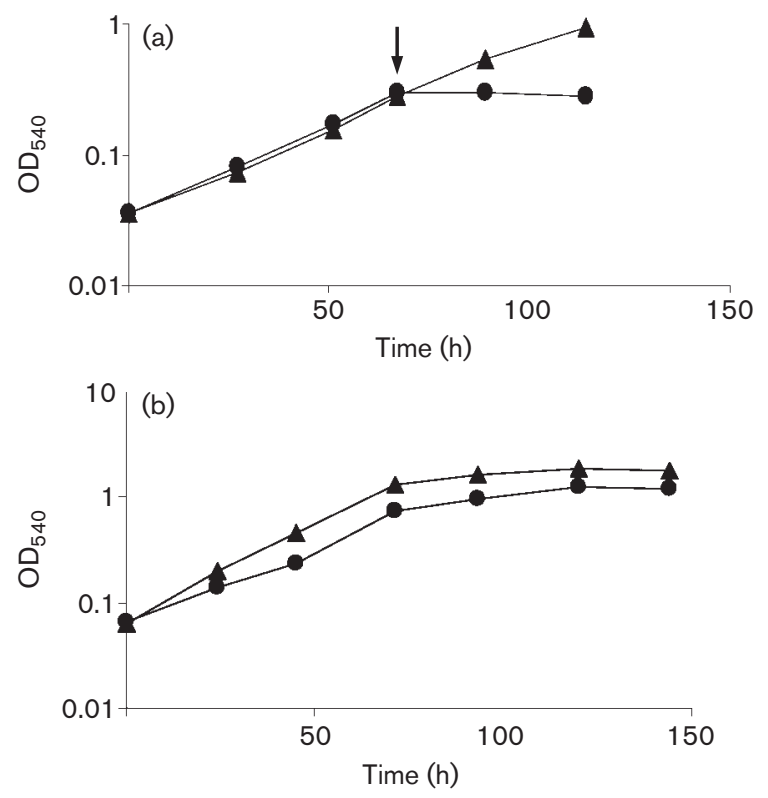

Fig. 1. Growth curve of M. tuberculosis in the presence (0) or absence $(\boldsymbol{\Delta})$ of vancomycin. The vertical arrow in (a) indicates the time at which the drug $\left(400 \mu \mathrm{g} \mathrm{ml}^{-1}\right)$ was added to one of the two cultures. Cultures in (b) were grown without or with $5 \mu \mathrm{g}$ vancomycin $\mathrm{ml}^{-1}$. Cultures for RNA extraction were harvested at $\mathrm{OD}_{540}$ of $0.2-0.3$.

which bacterial culture at an $\mathrm{OD}_{540}$ of 0.2 was added to vancomycin at a concentration 10X-MIC, incubated for $30 \mathrm{~min}, 1 \mathrm{~h}, 2 \mathrm{~h}$ or $4 \mathrm{~h}$, and then analysed to identify which genes were differentially expressed (data not shown). Under these conditions bacterial replication arrested rapidly (Fig. 1a), while the viable counts remained constant $\left(4.1 \pm 0.4 \times 10^{7}\right.$ and $3.7 \pm 0.2 \times 10^{7}$ at time 0 and $4 \mathrm{~h}$, respectively). We discarded the first time point $(30 \mathrm{~min})$, since very few genes, if any, were shown to be differentially regulated; time point $2 \mathrm{~h}$ was discarded since its expression profile was quite similar to the previous one $(1 \mathrm{~h})$ (data not shown). The analysis was than repeated on different biological samples exposed to vancomycin for $1 \mathrm{~h}$ or $4 \mathrm{~h}$; in these conditions the number of differentially expressed genes was 59 and 153, respectively (see Supplementary Tables S1 and S2, available with the online version of this paper).

When similar experiments were performed in B. subtilis, 10 min exposure was enough to obtain the induction of 129 genes (Cao et al., 2002), suggesting that some time is required for vancomycin to cross the mycobacterial outer membrane and exert its action. Quantitative RT-PCR was used to validate the differential expression of selected genes (Supplementary Tables S2 and S3, available with the online version of this paper). An analysis of the DNA array datasets using HCL indicated that the gene expression profile obtained after exposing bacterial cells to 10X-MIC vancomycin for either $1 \mathrm{~h}$ or $4 \mathrm{~h}$ was not globally different, since these tested conditions grouped in the same cluster (Fig. 2a).
When bacterial cultures were grown in the presence of the subinhibitory concentration of the drug, 141 genes were found to be differentially expressed (Table S3). A comparison by HCL between this set of data and that obtained from cultures exposed to inhibitory concentration of vancomycin for $4 \mathrm{~h}$ highlighted the presence of two distinct clusters, indicating that their gene expression profile was globally different (Fig. $2 \mathrm{~b}$ ).

However, several genes were found to be commonly expressed under more than one condition. In particular, 20 genes were commonly regulated after exposure to vancomycin 10X-MIC for $1 \mathrm{~h}$ and $4 \mathrm{~h}$, while 30 genes were regulated both in the presence of vancomycin 10X-MIC for $4 \mathrm{~h}$ and when cells were grown in a subinhibitory concentration of the drug. Finally, nine genes were commonly regulated under all tested conditions (Fig. 3). These genes (Table 1) were all induced and encoded well-known stress proteins, such as Hsp and HtpX, and proteins of unknown functions. Among them were Rv2623, belonging to the UspA (universal stress proteins) family (O’Toole \& Williams, 2003); Rv0516c, predicted as a putative anti-anti-sigma factor; Rv1057, similar to an archaeal surface layer protein and containing a $\beta$-propeller domain that could be involved in cell-cell interaction; Rv2050, which is an orthologue of the RNA-polymerase-associated protein RbpA of Streptomyces coelicolor (Paget et al., 2001b); and PE20.

Hsp (also referred to as Acr2) belongs to the $\alpha$-crystallin family of molecular chaperones and is induced in several stress conditions such as heat shock, oxidative stress and uptake by macrophages (Schnappinger et al., 2003; Stewart et al., 2002). HtpX is a putative membrane-bound zinc metalloprotease that has been suggested to participate in the proteolytic quality control of membrane proteins (Rodrigue et al., 2006).

Proteins of the UspA family are encoded in the genomes of bacteria, archaea, fungi, protozoa and plants, but their biological and biochemical function is still not fully understood. They are characterized by the presence of a typical domain that occurs either in isolation or fused to

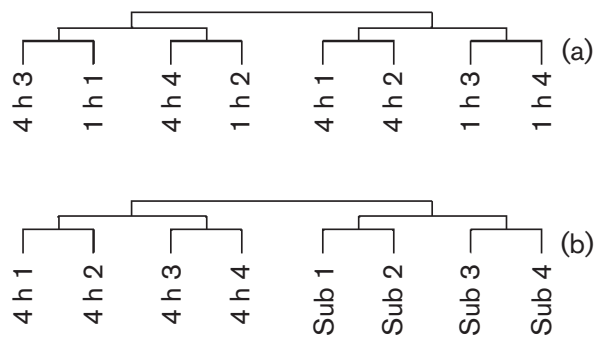

Fig. 2. Hierarchical clustering. (a) Clustering of gene profiles from M. tuberculosis cultures treated with $400 \mu \mathrm{g}$ vancomycin $\mathrm{ml}^{-1}$ for 1 or $4 \mathrm{~h}$. (b) Clustering of gene profiles from M. tuberculosis cultures treated for $4 \mathrm{~h}$ with $400 \mu \mathrm{g}$ vancomycin $\mathrm{ml}^{-1}$ or grown in the presence of $5 \mu \mathrm{g}$ vancomycin $\mathrm{ml}^{-1}$ (Sub). 


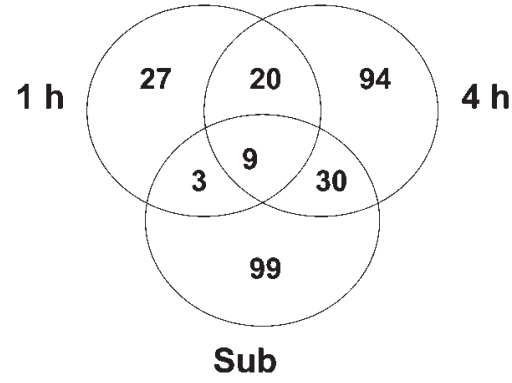

Fig. 3. Common and unique expression patterns of $M$. tuberculosis exposed to $400 \mu \mathrm{g}$ vancomycin $\mathrm{ml}^{-1}$ for $1 \mathrm{~h}$ or $4 \mathrm{~h}$, or exposed to $5 \mu \mathrm{g}$ vancomycin $\mathrm{ml}^{-1}$ (Sub). Venn diagram showing the number of $M$. tuberculosis genes differentially expressed in the different conditions.

other domains. In E. coli this family of proteins is represented by at least five paralogues that are induced by overlapping, but non-identical stresses. Interestingly, members of this family are involved in the regulation of bacterial growth, as they are important for recovery from starvation and their inactivation causes an extended lag when stationary-phase cells are transferred to fresh media (Kvint et al., 2003). Moreover, UspA production is strongly induced under conditions that cause growth arrest. The $M$. tuberculosis genome encodes at least eight proteins of this family (O’Toole \& Williams, 2003). Rv2623 contains two UspA typical domains, and it was previously shown to be part of the dormancy regulon and to be upregulated in mouse lungs at the terminal stage of pathology (Florczyk et al., 2001; Shi et al., 2003). Its induction by inhibitory and subinhibitory concentrations of vancomycin suggests its involvement in $M$. tuberculosis growth control following exposure to stress.
Rv0516c encodes a soluble protein with a typical anti-antisigma factor domain. It was one of the genes with the largest reduction in transcription during early stationaryphase growth of a $M$. tuberculosis mutant harbouring a deletion of the gene encoding $\sigma^{\mathrm{F}}$ (Geiman et al., 2004), and it has been shown to interact physically with this sigma factor in a two-hybrid system (Parida et al., 2005). Its coinduction with $\sigma^{\mathrm{E}}$ opens the interesting hypothesis that this protein could be involved in the regulation of the activity of this sigma factor. Several attempts to express this protein in $M$. tuberculosis were unsuccessful, suggesting its toxicity (data not shown).

Rv2050 is an orthologue of RbpA, an RNA-polymeraseassociated protein described in S. coelicolor, whose structural gene is induced by SigR in response to disulfide stress (Paget et al., 2001a). Orthologues of this protein are only found in actinomycetes. Recently, it was shown that this gene is also induced by rifamicin, and that RbpA is able to stimulate the expression of the rRNA operon even in the presence of rifamicin, conferring a basal level of resistance to this drug (Newell et al., 2006). In M. tuberculosis, Rv2050 was shown to be under the transcriptional control of SigH (SigR orthologue) and upregulated after heat shock and disulfide stress (Manganelli et al., 2002). The finding that the expression of this gene is also induced by vancomycin suggests that Rv2050 might contribute to the basal level of drug resistance in mycobacteria as well, opening the possibility to consider it as a novel drug-target candidate.

The PE20 structural gene (Rv1806) displayed a very strong induction in all tested conditions. Moreover, this gene (together with its downstream gene encoding PPE31) was previously shown to be induced after exposure to SDS (Manganelli et al., 2001), suggesting that these two proteins may have a specific role in surface stress response. Rv1807 (encoding PPE31) was induced after both 1 and $4 \mathrm{~h}$ of

Table 1. Genes induced in all conditions tested

Rv1807 was not included in this table since microarray data did not select it as an induced gene in cultures exposed to subinhibitory concentrations of vancomycin. However, RT-PCR data later showed that this was due to a technical problem (see text).

\begin{tabular}{|c|c|c|c|c|c|}
\hline Rv number & Gene $^{*}$ & $\begin{array}{l}\text { Fold induction } \\
\qquad\left(\begin{array}{ll}1 & h\end{array}\right) \dagger\end{array}$ & $\begin{array}{l}\text { Fold induction } \\
\qquad(4 \mathbf{h}) \dagger\end{array}$ & $\begin{array}{l}\text { Fold induction } \\
\qquad(\mathrm{S}) \dagger\end{array}$ & Gene product/function \\
\hline Rv0251c & $h s p$ & $2.4(0)$ & $8.3(0)$ & $6.3(0)$ & Molecular chaperone \\
\hline RV0516c & & $1.8(0)$ & $4.0(0)[9.5]$ & $1.6(0)$ & Putative anti-anti-sigma \\
\hline Rv0563 & $h t p X$ & $1.6(0)$ & $4.5(0)$ & $2.9(0)$ & Membrane-bound zinc metalloprotease \\
\hline Rv1057 & & $1.6(0)$ & $2.9(0)$ & $1.7(0)$ & Unknown function \\
\hline Rv1073 & & $1.7(0)$ & $3.1(0)$ & $1.8(0)$ & Unknown function \\
\hline Rv1806 & pe20 & $21.6(4)$ & $6.9(0)[56.3]$ & $191.9(0)[83.5]$ & Unknown function \\
\hline Rv2050 & & $1.6(0)$ & $2.4(0)$ & $1.9(0)$ & Putative RNApol associated protein \\
\hline Rv2623 & & $1.9(0)$ & $2.0(0.2)[2.2]$ & $16.0(0)[2.7]$ & Member of UspA family \\
\hline Rv2745c & & $1.9(0)$ & $2.1(0)$ & $3.0(0)$ & Putative transcriptional regulator \\
\hline
\end{tabular}

${ }^{*}$ Genes are annotated as described by the Pasteur Institute on TUBERCULIST (http://genolist.pasteur.fr/TubercuList/).

$†$ Values in parentheses represent false discovery rate (FDR), the probability that the gene was falsely called (calculated by SAM); values in square brackets represent the fold induction obtained by qRT-PCR. S, subinhibitory concentration. 
exposure to vancomycin. Although the microarray data did not indicate it as an induced gene in cultures exposed to subinhibitory concentrations of vancomycin, quantitative RT-PCR revealed that it was induced as well (tenfold) under this condition (Table S3). Interestingly, in a recent report the PE20-PPE31 couple was found to be a vaccine candidate able to confer a significant level of protection in a guinea pig aerosol infection model (Vipond et al., 2006). PE and PPE are two families of surface-associated proteins of unknown function typical of mycobacteria, characterized by conserved N-terminal domains (Gey van Pittius et al., 2006). Several PPE-encoding genes are in tandem with a sequence encoding a PE, and in one case the PE and the PPE proteins were shown to form a dimer (Strong et al., 2006).

\section{Genes induced after exposure to 10X-MIC vancomycin}

A total of 153 genes were differentially expressed during exposure to 10X-MIC vancomycin. Of these, 110 genes were upregulated and 43 were downregulated (Table S2). As indicated in Fig. 4(a), the most represented functional categories of induced genes include genes encoding conserved hypothetical proteins with unknown function $(36 \%)$ and genes involved in intermediary metabolism (13.5\%).

Genes involved in metabolism. Several genes involved in defence against xenobiotics and oxidative stress, as well as genes typically induced during growth arrest, were upregulated: $c y s D$ and $c y s N C$ encode an ATP sulfurylase, which catalyses the synthesis of activated sulfate (APS), which is then phosphorylated at the $3^{\prime}$ hydroxyl to form PAPS. This last compound can transfer sulfuryl groups to various metabolic recipients and is widely used by cells to regulate metabolism. Alternatively, the sulfuryl moiety of PAPS can be reduced to sulfide and incorporated into cysteine and, from there, into other reduced-sulfur metabolites. It has been shown previously that the cysDNC operon is induced upon oxidative stress, in stationary phase and in the intra-phagosomal milieu, suggesting regulation of sulfur assimilation in response to toxic oxidants (Hampshire et al., 2004; Pinto et al., 2004). Interestingly sulfolipids, important mycobacterial surface components able to inhibit phagosome-lysosome fusion, are sulfated by PAPS (Pinto et al., 2004), suggesting a role of the cysDNC operon also in determining surface composition.

Other metabolic genes involved in oxidative stress response induced in these conditions are trxB1, encoding a thioredoxin; $b f r B$, encoding a bacterioferritin, whose role could be required to remove the ferrous ions that can react with metabolically generated hydrogen peroxide to yield very toxic hydroxyl radicals, and a group including $i c l$, $p d h A, s c o A, n d h$ and narU. The proteins encoded by these genes use and regenerate reducing equivalents from fatty acids in the absence of external electron acceptors (icl, $p d h A$ and scoA) (Boshoff \& Barry, 2005), or during the microaerophilic respiration that is typical of cultures subjected to severe nutrient starvation or slow growth (ndh, narU) (Boshoff \& Barry, 2005; Clegg et al., 2006).

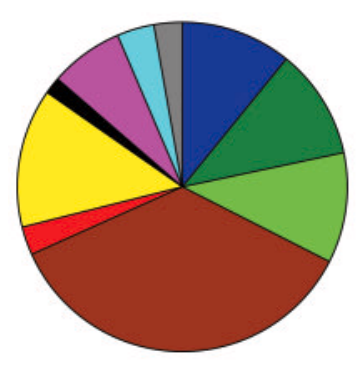

(a)

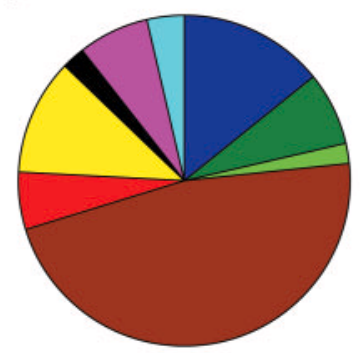

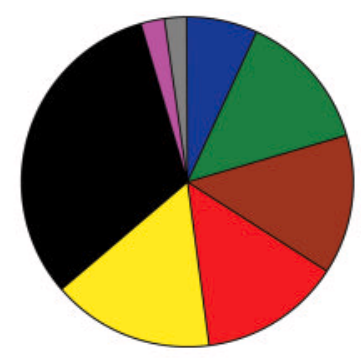

(b)
Broad regulatory functions

口 Cell wall/cell processes

$\square$ Chaperone/heat shock

घ Conserved hypotheticals

a Information pathway

$\square$ Intermediary metabolism and respiration

- Lipid metabolism

口PE/PPE

$\square$ Phage-related functions

口 Virulence/adaptation/detoxification

(c)

Fig. 4. Functional categories of genes upregulated (a) or downregulated (b) after exposure to $400 \mu \mathrm{g}$ vancomycin $\mathrm{ml}^{-1}$ for $4 \mathrm{~h}$; (c) functional categories of genes upregulated in $M$. tuberculosis cultures grown in the presence of $5 \mu \mathrm{g}$ vancomycin $\mathrm{ml}^{-1}$. 
Cell wall and cell processes. Rv2743c, encoding a conserved transmembrane protein, was found to be induced together with the upstream genes Rv2745c and Rv2744c. This putative operon was upregulated in $M$. tuberculosis also after treatment with SDS and its transcription is under the control of the ECF sigma factor $\sigma^{\mathrm{E}}$ (Manganelli et al., 2001); Rv2745c is predicted to be a transcriptional regulatory protein, whereas Rv2744c is highly homologous to the E. coli PspA (phage-shock protein A) (Rodrigue et al., 2006). In E. coli, PspA is part of a cytoplasmic membrane protection system involved in suppressing proton leakage from damaged membranes (Kobayashi et al., 2007). In the presence of a specific surface stress signal (a decrease of the proton-motive force due to cytoplasmic membrane permeabilization), a transmembrane protein activates PspA, which releases the transcriptional factor $\mathrm{PspF}$ and associates with the internal surface of the cytoplasmic membrane, causing its stabilization (Darwin, 2005). Although Rv2745c and Rv2743c do not share any similarity with the transcriptional regulator and the transmembrane protein, respectively, involved in the E. coli PspA system, it is tempting to speculate that they represent their functional analogues. Experiments to address this issue are currently under development in our laboratory. The gene Rv0116c encodes a surface protein of unknown function containing a peptidoglycan-binding domain and is induced also in cells exposed to subinhibitory concentration of the drug. Even though the function of this protein is unknown, it is possible to hypothesize that it is involved in the biogenesis or structural organization of the cell wall, making it an interesting candidate for future studies. mmpL5-mmpS5 encode proteins resembling efflux pumps belonging to the resistance-nodulation-division (RND) family (Cole et al., 1998). The genome sequence of $M$. tuberculosis contains 14 genes encoding putative transport proteins of the RND superfamily (Jain et al., 2008). Interestingly, these two genes are also induced in response to SDS-mediated surface stress (Manganelli et al., 2001), and recently their overexpression has been found to be responsible for azole resistance via an efflux mechanism (Milano et al., 2009). Involvement of inner-membrane efflux pumps in response to drugs targeting peptidoglycan biosynthesis is commonly accepted even if difficult to explain, since these drugs do not need to enter inside the cell to exert their action (Danilchanka et al., 2008).

Beyond the genes encoding the coupled PE20-PPE31, also the genes encoding the coupled PE35-PPE68 (part of the Esx-1 cluster), PPE32, PPE33, PE17 and PE_PGRS30 were induced in these conditions, underscoring the importance of these surface-associated protein families in the biology of the mycobacterial envelope.

Chaperones and protein degradation. Besides $h s p$ and $h t p X$, which have been mentioned before, several other chaperone-encoding genes were induced by 10X-MIC vancomycin, suggesting that high concentrations of this drug promote protein misfolding or aggregation, probably due to growth arrest. $h s p X$ (a paralogue of $h s p$, referred to as acr1) encodes a protein belonging to the $\alpha$-crystallin family of molecular chaperones, which is associated with in vivo growth and persistence (Timm et al., 2003) and with microaerophilic conditions (Desjardin et al., 2001). hspX has been proposed to play an active role in slowing the growth of $M$. tuberculosis in vivo immediately following infection. Other chaperone-encoding induced genes were dnaK, grpE, dnaJI, groEL1, groEL2, groES and clpB, whose protein products have been shown to interact with each other in order to prevent protein aggregation and support the refolding of damaged proteins (Dougan et al., 2002). Only one gene involved in protein degradation was induced: Rv2115c (mpa); this gene encodes an AAA ATPase forming ring-shaped complexes homologous to those found in proteasome caps of eukaryotes and was shown to have a role in oxidative stress response and in virulence (Darwin et al., 2005).

Toxin-antitoxin systems. Four genes encoding two toxinantitoxin (TA) protein pairs (Rv0550c-Rv0549c and Rv1991c-Rv1990c) and four genes encoding proteins related to toxic components of TA systems (Rv1720c, Rv2142c, Rv2602 and Rv2865) were found to be induced. TA systems are widespread in prokaryotes and are usually organized in operons composed of two genes in which the first ORF usually encodes an antitoxin that combines with and neutralizes a regulatory 'toxin' encoded by the second ORF. Typically, expression of the operon is negatively autoregulated by the antitoxin or by an antitoxin-toxin complex (Magnuson, 2007). TA systems were originally characterized as factors encoded by low-copy-number plasmids to eliminate plasmid-free cells emerging as a result of segregation or replication defects, ensuring plasmid dissemination among bacteria (Gerdes et al., 1986; Jaffe et al., 1985). TA modules are also widespread on bacterial chromosomes. These chromosomal TA cassettes (cTAs) are homologous to those identified on plasmids but apparently fulfil different functions. Experimental evidence suggests that cTAs are stress-response elements that help cells to survive adverse growth conditions by attenuation of protein synthesis and retardation of cell growth. In response to environmental stress, the antitoxin is degraded by host proteases, thereby causing an increased expression of the toxin, whose activity promotes slow growth (Hayes, 2003; Pandey \& Gerdes, 2005). Interestingly, TA systems are over-represented in the genomes of slowly growing bacteria (Pandey \& Gerdes, 2005). M. tuberculosis $\mathrm{H} 37 \mathrm{Rv}$ contains 38 TA loci on its chromosome, suggesting that their biological functions are particularly beneficial to this micro-organism, which is able to arrest growth during intracellular phases of its life cycle (Arcus et al., 2005). Indeed, TA pairs have been found to be part of the dormancy regulon and are induced by hypoxia and subinhibitory concentrations of nitric oxide (Voskuil et al., 2004). The induction of TA genes after exposure to vancomycin suggests that these proteins play an important 
role in regulating the growth rate of mycobacteria in response to diverse stress conditions, and also suggests that they could act as cell cycle arrest factors that induce cells to enter a dormant state as a protection against an adverse environment.

Regulatory proteins. As indicated in Table S2, we noted that several genes regulated by the surface stress-specific alternative ECF sigma factor $\sigma^{\mathrm{E}}$ were induced, suggesting a role of this regulator in the response to this drug. However, unexpectedly, sigE did not appear as one of the significantly upregulated genes. To determine whether this was an artefact due to the microarray technique, we measured sigE mRNA levels by quantitative real-time PCR. We found that sigE was indeed induced when cells were treated with both inhibitory and subinhibitory concentrations of vancomycin (Tables S2 and S3). Accordingly, sigB, Rv0465c and Rv0516c, encoding other regulators already shown to be downstream of $\sigma^{\mathrm{E}}$, were induced as well in these conditions.

Finally, another interesting gene induced under these conditions is represented by whiB6, whose product belongs to a family of small transcriptional regulators typical of Streptomyces and other actinomycetes. This gene has been recently shown to be induced after exposure to surface stress (SDS, ethanol), oxidative stress (diamide, cumene peroxide) and heat shock (Geiman et al., 2006). Members of this family have been shown to be involved in differentiation, spore formation and septation in Streptomyces (Soliveri et al., 2000).

\section{Genes repressed after exposure to 10X-MIC vancomycin}

As shown in Fig. 4(b), the treatment with 10X-MIC vancomycin induced a strong repression of genes required for lipid metabolism $(32 \%)$. In particular, we found a strong repression of the $p p s A B C D E$ and $d r A B C$ operons, which are responsible for dimycocerosate biosynthesis and transport (Azad et al., 1997); kasAB and accD6, involved in the biosynthesis of mycolic acids, were strongly repressed as well, together with other genes involved in lipid synthesis ( $p k s 1, p k s 6, p k s 15$, fadD22 and desA2). These data suggest that under conditions of growth arrest bacteria slow down the synthesis of energy-expensive cell-wall components. Additional genes involved in metabolic pathways were $n u o M$ and $n u o N$, encoding two subunits of a NADH dehydrogenase typically expressed during rapid growth in aerobiosis. Their repression fits well with the induction of $n d h$, which encodes a protein with similar function, but typical of slow, microaerophilic growth (Boshoff et al., 2004; Boshoff \& Barry, 2005). hemB, hemD and hemZ encode enzymes responsible for the biosynthesis of haem, an oxygen-binding prosthetic group contained in several proteins involved in cytoplasmic metabolic pathways; hem $Z$ was recently shown to be an essential gene in $M$. tuberculosis (Parish et al., 2005). rpfE encodes a protein homologous to the resuscitation-promoting factor ( $r p f)$ gene of Micrococcus luteus, whose product is required to resuscitate the growth of dormant cultures of this bacterium. The $M$. tuberculosis genome contains five genes with significant homology to $r p f$. Even though null mutations in single $r p f$ genes did not affect $M$. tuberculosis physiology, suggesting some redundancy of functions, multiple rpf mutations significantly attenuated $M$. tuberculosis virulence in a mouse infection model. These mutants were also unable to resuscitate spontaneously in vitro, demonstrating the importance of the Rpf-like proteins of $M$. tuberculosis in resuscitation from the nonculturable state (Downing et al., 2005). Finally, several genes encoding ribosomal proteins were downregulated, suggesting a reduced rate of protein synthesis in these conditions.

Taken together, these data suggest that in the presence of 10X-MIC vancomycin, $M$. tuberculosis undergoes a strong stress response involving $\sigma^{\mathrm{E}}$-mediated membrane stability protection, and a protein refolding programme. Interestingly, several genes that we found induced are also induced in conditions of slow growth and low oxygen tension. Metabolism is slowed down, probably by the action of TA systems and Rv2623 (UspA-like), reducing the synthesis of proteins and energy-expensive surface lipids and shifting to a microaerophilic lifestyle. Of great interest is the induction in these conditions of the genes encoding two coupled PEPPE proteins and four other non-linked PE/PPE genes of this family. Since the function of these families of surfaceassociated proteins is still unknown, vancomycin-treated cultures could represent a simple model to study their function in detail. Experiments to address this issue are in progress in our laboratory. The overall result of this transcriptional response could help the bacteria to partially avoid being killed by the bactericidal action of vancomycin.

\section{sigE confers basal protection to vancomycin}

sigE was induced by vancomycin; in order to determine its importance in the response to this drug-mediated stress, we tested the sensitivity of a sigE mutant to this drug in an agar diffusion assay. As shown in Table 2, the mutant was more sensitive to vancomycin as compared to the wild-type parental strain. This phenotype was totally complemented when the wild-type gene was reintroduced at an ectopic locus on the chromosome, showing that the transcriptional response due to this alternative sigma factor is indeed able to alleviate the toxic action produced by this drug.

\section{Genes differentially expressed in cultures growing 1/8-MIC vancomycin}

In the presence of subinhibitory concentrations of vancomycin, a total of 141 genes were differentially expressed. Functional categories of the upregulated genes are shown in Fig. 4(c). The most represented category was that of the conserved hypothetical proteins with unknown 
function $(46.8 \%)$, followed by that of genes involved in broad regulatory functions $(14.2 \%)$, most of which are required for transcriptional regulation (Table S3). Only four repressed genes were identified.

While the pattern of gene expression after exposure to 10XMIC vancomycin gave some clear hints of the physiological conditions of the bacteria, results obtained with cultures exposed to the $1 / 8$-MIC of the drug were more difficult to interpret. Some of the stress-response genes induced by 10X-MIC vancomycin, such as $c l p B$, $h s p$, $h t p X$, were induced also in these conditions, suggesting that cells were indeed exposed to stress, even if still able to divide. The induction of Rv2623, encoding a UspA-like protein, is interesting, since its upregulation was previously associated only with conditions of growth arrest (Florczyk et al., 2001; Shi et al., 2003), while our data suggest that its activity is also required for active growth under certain stress conditions. Cultures exposed to subinhibitory vancomycin concentrations will represent a valuable model to study the function of this interesting gene. Other genes induced in these conditions include ethR-ethA, encoding a monooxygenase responsible for the activation of ethionamide and its transcriptional repressor. Interestingly, the induction of these two genes was also observed after SDS-mediated surface stress (Manganelli et al., 2001). Other induced genes included parB, encoding a chromosome-partitioning protein; Rv0116c (induced also at high vancomycin concentration), encoding a protein with a peptidoglycanbinding domain; lat, encoding an L-lysine $\varepsilon$-aminotransferase; $r s b W$, and Rv3288c, which were reported as being strongly induced in conditions of long starvation and stationary phase (Bacon et al., 2004; Betts et al., 2002).

The transcriptional response to vancomycin was compared to those detected in response to acidic $\mathrm{pH}$ (Fisher et al., 2002), the thiol-specific oxidating agent diamide (Manganelli et al., 2002), SDS (Manganelli et al., 2001), nitric oxide (Ohno et al., 2003), heat shock (Stewart et al., 2002) and non-replicative persistence (NRP) (Muttucumaru et al., 2004). As shown in Table S4, $46 \%$ of the genes induced by SDS and $41 \%$ of those induced after heat shock were also induced by vancomycin in at least one of the conditions tested; the overlap with the genes induced in the other stress

Table 2. Sensitivity to vancomycin in a disc diffusion assay

The paper discs contained $100 \mu \mathrm{g}$ vancomycin. The experiment, performed in triplicate, was repeated twice with independent bacterial cultures.

\begin{tabular}{|lc|}
\hline Strain & Inhibition zone diameter $(\mathbf{c m})^{*}$ \\
\hline H37Rv & $3.5 \pm 0.1$ \\
sigE mutant & $5.0 \pm 0.2$ \\
sigE mutant compl. & $3.5 \pm 0.1$ \\
\hline
\end{tabular}

${ }^{\star}$ Mean $\pm \mathrm{SD}$. conditions was lower. Table S5 shows the genes induced in all three vancomycin conditions, and their induction by other stresses. Interestingly, also in this case the highest overlap was with SDS and heat shock, suggesting some common features between conditions experienced by the bacteria during exposure to stresses of this kind and those experienced during growth with vancomycin.

\section{Conclusions}

By analysing the variation of the global transcription profile of $M$. tuberculosis cultures exposed to inhibitory or subinhibitory concentrations of a drug that perturbs surface homeostasis, we demonstrated that the responses to these different conditions are different, although with some overlap. This approach allowed us to identify several genes whose products could be involved in the protection from antibiotic stress targeting the envelope and help to confer the basal level of $M$. tuberculosis resistance to antibacterial drugs. Some of them, such as those encoding Rv2623 (UspA-like), Rv0116c, PE20-PPE31, PspA and the toxinantitoxin systems, will be very promising subjects for future studies to better understand the physiology of the mycobacterial envelope and could represent new drug targets. Moreover, our findings demonstrate that $\sigma^{\mathrm{E}}$ confers basal resistance to vancomycin, once again underlining its importance in the physiology of the mycobacterial surface stress response (Raman et al., 2008).

\section{ACKNOWLEDGEMENTS}

This work was supported by MIUR-COFIN 2006, grant no. 2006064583 (awarded to R. M.), and from the University of Padua, 'Progetto Giovani Ricercatori' (awarded to R. P.) The authors wish to thank Issar Smith for useful discussion and for carefully reading the manuscript.

\section{REFERENCES}

Arcus, V. L., Rainey, P. B. \& Turner, S. J. (2005). The PIN-domain toxin-antitoxin array in mycobacteria. Trends Microbiol 13, 360-365.

Azad, A. K., Sirakova, T. D., Fernandes, N. D. \& Kolattukudy, P. E. (1997). Gene knockout reveals a novel gene cluster for the synthesis of a class of cell wall lipids unique to pathogenic mycobacteria. J Biol Chem 272, 16741-16745.

Bacon, J., James, B. W., Wernisch, L., Williams, A., Morley, K. A., Hatch, G. J., Mangan, J. A., Hinds, J., Stoker, N. G. \& other authors (2004). The influence of reduced oxygen availability on pathogenicity and gene expression in Mycobacterium tuberculosis. Tuberculosis (Edinb) 84, 205-217.

Barry, C. E., III (2001). Interpreting cell wall 'virulence factors' of Mycobacterium tuberculosis. Trends Microbiol 9, 237-241.

Betts, J. C., Lukey, P. T., Robb, L. C., McAdam, R. A. \& Duncan, K. (2002). Evaluation of a nutrient starvation model of Mycobacterium tuberculosis persistence by gene and protein expression profiling. Mol Microbiol 43, 717-731.

Boshoff, H. I. \& Barry, C. E., III (2005). Tuberculosis - metabolism and respiration in the absence of growth. Nat Rev Microbiol 3, 70-80. 
Boshoff, H. I., Myers, T. G., Copp, B. R., McNeil, M. R., Wilson, M. A. \& Barry, C. E., III (2004). The transcriptional responses of Mycobacterium tuberculosis to inhibitors of metabolism: novel insights into drug mechanisms of action. J Biol Chem 279, 40174-40184.

Cao, M., Wang, T., Ye, R. \& Helmann, J. D. (2002). Antibiotics that inhibit cell wall biosynthesis induce expression of the Bacillus subtilis SigW and SigM regulons. Mol Microbiol 45, 1267-1276.

Clegg, S. J., Jia, W. \& Cole, J. A. (2006). Role of the Escherichia coli nitrate transport protein, NarU, in survival during severe nutrient starvation and slow growth. Microbiology 152, 2091-2100.

Cole, S. T., Brosch, R., Parkhill, J., Garnier, T., Churcher, C., Harris, D., Gordon, S. V., Eiglmeier, K., Gas, S. \& other authors (1998). Deciphering the biology of Mycobacterium tuberculosis from the complete genome sequence. Nature 393, 537-544.

Danilchanka, O., Mailaender, C. \& Niederweis, M. (2008). Identification of a novel multidrug efflux pump of Mycobacterium tuberculosis. Antimicrob Agents Chemother 52, 2503-2511.

Darwin, A. J. (2005). The phage-shock-protein response. Mol Microbiol 57, 621-628.

Darwin, K. H., Lin, G., Chen, Z., Li, H. \& Nathan, C. F. (2005). Characterization of a Mycobacterium tuberculosis proteasomal ATPase homologue. Mol Microbiol 55, 561-571.

Desjardin, L. E., Hayes, L. G., Sohaskey, C. D., Wayne, L. G. \& Eisenach, K. D. (2001). Microaerophilic induction of the alphacrystallin chaperone protein homologue $(h s p X)$ mRNA of $M y c o-$ bacterium tuberculosis. J Bacteriol 183, 5311-5316.

Dougan, D. A., Mogk, A. \& Bukau, B. (2002). Protein folding and degradation in bacteria: to degrade or not to degrade? That is the question. Cell Mol Life Sci 59, 1607-1616.

Downing, K. J., Mischenko, V. V., Shleeva, M. O., Young, D. I., Young, M., Kaprelyants, A. S., Apt, A. S. \& Mizrahi, V. (2005). Mutants of Mycobacterium tuberculosis lacking three of the five $r p f$-like genes are defective for growth in vivo and for resuscitation in vitro. Infect Immun 73, 3038-3043.

Dye, C., Scheele, S., Dolin, P., Pathania, V. \& Raviglione, M. C. (1999). Consensus statement. Global burden of tuberculosis: estimated incidence, prevalence, and mortality by country. WHO Global Surveillance and Monitoring Project. JAMA 282, 677-686.

Fisher, M. A., Plikaytis, B. B. \& Shinnick, T. M. (2002). Microarray analysis of the Mycobacterium tuberculosis transcriptional response to the acidic conditions found in phagosomes. J Bacteriol 184, 4025-4032.

Florczyk, M. A., McCue, L. A., Stack, R. F., Hauer, C. R. \& McDonough, K. A. (2001). Identification and characterization of mycobacterial proteins differentially expressed under standing and shaking culture conditions, including Rv2623 from a novel class of putative ATP-binding proteins. Infect Immun 69, 5777-5785.

Gandhi, N. R., Moll, A., Sturm, A. W., Pawinski, R., Govender, T., Lalloo, U., Zeller, K., Andrews, J. \& Friedland, G. (2006). Extensively drug-resistant tuberculosis as a cause of death in patients co-infected with tuberculosis and HIV in a rural area of South Africa. Lancet 368, 1575-1580.

Geiman, D. E., Kaushal, D., Ko, C., Tyagi, S., Manabe, Y. C., Schroeder, B. G., Fleischmann, R. D., Morrison, N. E., Converse, P. J. \& other authors (2004). Attenuation of late-stage disease in mice infected by the Mycobacterium tuberculosis mutant lacking the SigF alternate sigma factor and identification of SigF-dependent genes by microarray analysis. Infect Immun 72, 1733-1745.

Geiman, D. E., Raghunand, T. R., Agarwal, N. \& Bishai, W. R. (2006). Differential gene expression in response to exposure to antimycobacterial agents and other stress conditions among seven Mycobacterium tuberculosis whiB-like genes. Antimicrob Agents Chemother 50, 2836-2841.
Gerdes, K., Rasmussen, P. B. \& Molin, S. (1986). Unique type of plasmid maintenance function: postsegregational killing of plasmidfree cells. Proc Natl Acad Sci U S A 83, 3116-3120.

Gey van Pittius, N. C., Sampson, S. L., Lee, H., Kim, Y., van Helden, P. D. \& Warren, R. M. (2006). Evolution and expansion of the Mycobacterium tuberculosis PE and PPE multigene families and their association with the duplication of the ESAT-6 (esx) gene cluster regions. BMC Evol Biol 6, 95.

Hampshire, T., Soneji, S., Bacon, J., James, B. W., Hinds, J., Laing, K., Stabler, R. A., Marsh, P. D. \& Butcher, P. D. (2004). Stationary phase gene expression of Mycobacterium tuberculosis following a progressive nutrient depletion: a model for persistent organisms? Tuberculosis (Edinb) 84, 228-238.

Hayes, F. (2003). Toxins-antitoxins: plasmid maintenance, programmed cell death, and cell cycle arrest. Science 301, 1496-1499.

Hoffmann, C., Leis, A., Niederweis, M., Plitzko, J. M. \& Engelhardt, H. (2008). Disclosure of the mycobacterial outer membrane: cryoelectron tomography and vitreous sections reveal the lipid bilayer structure. Proc Natl Acad Sci U S A 105, 3963-3967.

Jacobs, W. R., Jr, Kalpana, G. V., Cirillo, J. D., Pascopella, L., Snapper, S. B., Udani, R. A., Jones, W., Barletta, R. G. \& Bloom, B. R. (1991). Genetic systems for mycobacteria. Methods Enzymol 204, 537-555.

Jaffe, A., Ogura, T. \& Hiraga, S. (1985). Effects of the ccd function of the F plasmid on bacterial growth. J Bacteriol 163, 841-849.

Jain, M. J., Chow, E. D. \& Cox, J. (2008). The MmpL proteins. In The Mycobacterial Cell Envelope, pp. 201-210. Edited by M. Daffé \& J. M. Reyrat. Washington, DC: American Society for Microbiology.

Kobayashi, R., Suzuki, T. \& Yoshida, M. (2007). Escherichia coli phage-shock protein A (PspA) binds to membrane phospholipids and repairs proton leakage of the damaged membranes. Mol Microbiol 66, 100-109.

Kvint, K., Nachin, L., Diez, A. \& Nystrom, T. (2003). The bacterial universal stress protein: function and regulation. Curr Opin Microbiol 6, 140-145.

Maciag, A., Dainese, E., Rodriguez, G. M., Milano, A., Provvedi, R., Pasca, M. R., Smith, I., Palù, G., Riccardi, G. \& Manganelli, R. (2007). Global analysis of the Mycobacterium tuberculosis Zur (FurB) regulon. J Bacteriol 189, 730-740.

Magnuson, R. D. (2007). Hypothetical functions of toxin-antitoxin systems. J Bacteriol 189, 6089-6092.

Manganelli, R., Dubnau, E., Tyagi, S., Kramer, F. R. \& Smith, I. (1999). Differential expression of 10 sigma factor genes in Mycobacterium tuberculosis. Mol Microbiol 31, 715-724.

Manganelli, R., Voskuil, M. I., Schoolnik, G. K. \& Smith, I. (2001). The Mycobacterium tuberculosis ECF sigma factor SigE: role in global gene expression and survival in macrophages. Mol Microbiol 41, 423-437.

Manganelli, R., Voskuil, M. I., Schoolnik, G. K., Dubnau, E., Gomez, M. \& Smith, I. (2002). Role of the extracytoplasmic-function sigma factor SigH in Mycobacterium tuberculosis global gene expression. Mol Microbiol 45, 365-374.

Mascher, T., Margulis, N. G., Wang, T., Ye, R. W. \& Helmann, J. D. (2003). Cell wall stress responses in Bacillus subtilis: the regulatory network of the bacitracin stimulon. Mol Microbiol 50, 1591-1604.

Milano, A., Pasca, M. R., Provvedi, R., Lucarelli, A. P., Manina, G., de Jesus Lopes Ribeiro, A. L., Manganelli, R. \& Riccardi, G. (2009). Azole resistance in Mycobacterium tuberculosis is mediated by the MmpS5-MmpL5 efflux system. Tuberculosis (Edinb) 89, 84-90.

Muttucumaru, D. G., Roberts, G., Hinds, J., Stabler, R. A. \& Parish, T. (2004). Gene expression profile of Mycobacterium tuberculosis in a non-replicating state. Tuberculosis (Edinb) 84, 239-246. 
Newell, K. V., Thomas, D. P., Brekasis, D. \& Paget, M. S. (2006). The RNA polymerase-binding protein RbpA confers basal levels of rifampicin resistance on Streptomyces coelicolor. Mol Microbiol 60, 687-696.

Ohno, H., Zhu, G., Mohan, V. P., Chu, D., Kohno, S., Jacobs, W. R., Jr \& Chan, J. (2003). The effects of reactive nitrogen intermediates on gene expression in Mycobacterium tuberculosis. Cell Microbiol 5, 637-648.

O'Toole, R. \& Williams, H. D. (2003). Universal stress proteins and Mycobacterium tuberculosis. Res Microbiol 154, 387-392.

Paget, M. S., Bae, J. B., Hahn, M. Y., Li, W., Kleanthous, C., Roe, J. H. \& Buttner, M. J. (2001a). Mutational analysis of RsrA, a zinc-binding anti-sigma factor with a thiol-disulphide redox switch. Mol Microbiol 39, 1036-1047.

Paget, M. S., Molle, V., Cohen, G., Aharonowitz, Y. \& Buttner, M. J. (2001b). Defining the disulphide stress response in Streptomyces coelicolor A3(2): identification of the SigR regulon. Mol Microbiol 42, 1007-1020.

Pandey, D. P. \& Gerdes, K. (2005). Toxin-antitoxin loci are highly abundant in free-living but lost from host-associated prokaryotes. Nucleic Acids Res 33, 966-976.

Parida, S. K., Huygen, K., Ryffel, B. \& Chakraborty, T. (2005). Novel bacterial delivery system with attenuated Salmonella typhimurium carrying plasmid encoding $M t b$ antigen $85 \mathrm{~A}$ for mucosal immunization: establishment of proof of principle in TB mouse model. Ann NY Acad Sci 1056, 366-378.

Parish, T., Schaeffer, M., Roberts, G. \& Duncan, K. (2005). HemZ is essential for heme biosynthesis in Mycobacterium tuberculosis. Tuberculosis (Edinb) 85, 197-204.

Pinto, R., Tang, Q. X., Britton, W. J., Leyh, T. S. \& Triccas, J. A. (2004). The Mycobacterium tuberculosis cysD and cys $N C$ genes form a stressinduced operon that encodes a tri-functional sulfate-activating complex. Microbiology 150, 1681-1686.

Provvedi, R., Palù, G. \& Manganelli, R. (2008). Use of DNA microarrays to study global patterns of gene expression. In Mycobacteria Protocols, 2nd edn, pp. 95-110. Edited by T. Parish \& A. C. Brown. Totowa, NJ: Humana Press.

Raman, S., Cascioferro, A., Husson, R. \& Manganelli, R. (2008). Mycobacterial sigma factors and surface biology. In The Mycobacterial Cell Envelope, pp. 223-234. Edited by M. Daffé \& J. M. Reyrat. Washington, DC: American Society for Microbiology.

Raviglione, M. C. (2003). The TB epidemic from 1992 to 2002. Tuberculosis (Edinb) 83, 4-14.

Rodrigue, S., Provvedi, R., Jacques, P. E., Gaudreau, L. \& Manganelli, R. (2006). The sigma factors of Mycobacterium tuberculosis. FEMS Microbiol Rev 30, 926-941.

Schnappinger, D., Ehrt, S., Voskuil, M. I., Liu, Y., Mangan, J. A., Monahan, I. M., Dolganov, G., Efron, B., Butcher, P. D. \& other authors (2003). Transcriptional adaptation of Mycobacterium tuberculosis within macrophages: insights into the phagosomal environment. J Exp Med 198, 693-704.
Shi, L., Jung, Y. J., Tyagi, S., Gennaro, M. L. \& North, R. J. (2003). Expression of Th1-mediated immunity in mouse lungs induces a Mycobacterium tuberculosis transcription pattern characteristic of nonreplicating persistence. Proc Natl Acad Sci U S A 100, 241-246.

Soliveri, J. A., Gomez, J., Bishai, W. R. \& Chater, K. F. (2000). Multiple paralogous genes related to the Streptomyces coelicolor developmental regulatory gene whiB are present in Streptomyces and other actinomycetes. Microbiology 146, 333-343.

Stewart, G. R., Wernisch, L., Stabler, R., Mangan, J. A., Hinds, J., Laing, K. G., Young, D. B. \& Butcher, P. D. (2002). Dissection of the heat-shock response in Mycobacterium tuberculosis using mutants and microarrays. Microbiology 148, 3129-3138.

Strong, M., Sawaya, M. R., Wang, S., Phillips, M., Cascio, D. \& Eisenberg, D. (2006). Toward the structural genomics of complexes: crystal structure of a PE/PPE protein complex from Mycobacterium tuberculosis. Proc Natl Acad Sci U S A 103, 8060-8065.

Timm, J., Post, F. A., Bekker, L. G., Walther, G. B., Wainwright, H. C., Manganelli, R., Chan, W. T., Tsenova, L., Gold, B. \& other authors (2003). Differential expression of iron-, carbon-, and oxygenresponsive mycobacterial genes in the lungs of chronically infected mice and tuberculosis patients. Proc Natl Acad Sci U S A 100, 1432114326.

Tusher, V. G., Tibshirani, R. \& Chu, G. (2001). Significance analysis of microarrays applied to the ionizing radiation response. Proc Natl Acad Sci U S A 98, 5116-5121.

Utaida, S., Dunman, P. M., Macapagal, D., Murphy, E., Projan, S. J., Singh, V. K., Jayaswal, R. K. \& Wilkinson, B. J. (2003). Genome-wide transcriptional profiling of the response of Staphylococcus aureus to cell-wall-active antibiotics reveals a cell-wall-stress stimulon. Microbiology 149, 2719-2732.

Vaquerizas, J. M., Conde, L., Yankilevich, P., Cabezon, A., Minguez, P., Diaz-Uriarte, R., Al-Shahrour, F., Herrero, J. \& Dopazo, J. (2005). GEPAS, an experiment-oriented pipeline for the analysis of microarray gene expression data. Nucleic Acids Res 33, W616-W620.

Vipond, J., Clark, S. O., Hatch, G. J., Vipond, R., Marie Agger, E., Tree, J. A., Williams, A. \& Marsh, P. D. (2006). Re-formulation of selected DNA vaccine candidates and their evaluation as protein vaccines using a guinea pig aerosol infection model of tuberculosis. Tuberculosis (Edinb) 86, 218-224.

Voskuil, M. I., Visconti, K. C. \& Schoolnik, G. K. (2004). Mycobacterium tuberculosis gene expression during adaptation to stationary phase and low-oxygen dormancy. Tuberculosis (Edinb) 84, 218-227.

Wilson, M., DeRisi, J., Kristensen, H. H., Imboden, P., Rane, S., Brown, P. O. \& Schoolnik, G. K. (1999). Exploring drug-induced alterations in gene expression in Mycobacterium tuberculosis by microarray hybridization. Proc Natl Acad Sci U S A 96, 12833-12838.

Zuber, B., Chami, M., Houssin, C., Dubochet, J., Griffiths, G. \& Daffé, M. (2008). Direct visualization of the outer membrane of native mycobacteria and corynebacteria. J Bacteriol 190, 5672-5680.

Edited by: S. V. Gordon 